\title{
SCIENTIFIC REPRESENTATION AND REALISM
}

\author{
Michel GHINS \\ Université Catholique de Louvain
}

\begin{abstract}
After a brief presentation of what I take to be the representational démarche in science, I stress the fundamental role of true judgements in model construction. The success and correctness of a representation rests on the truth of judgements which attribute properties to real targeted entities, called "ontic judgements". I then present what van Fraassen calls "the Loss of Reality objection". After criticizing his dissolution of the objection, I offer an alternative way of answering the Loss of Reality objection by showing that the contact of our models with reality is grounded on the truth of ontic judgements. I conclude by examining the consequence of this view on the issue of scientific realism.
\end{abstract}

Keywords: Representation; realism; van Fraassen; model; judgements.

In Scientific Representation. Paradoxes of Perspective, Bas van Fraassen (2008) claims that scientific theories are in the first place representations and that the aim of science is to construct empirically adequate representations of phenomena. The novel terminology in which he chooses to couch the aim of science should not mislead us. Such a view essentially accords with the manner in which knowledge has been construed by modern thinkers. In the glorious $17^{\text {th }}$ century, when modern mathematical science blossomed, empiricist and rationalist philosophers alike proclaimed that to know is to represent. Galileo, Descartes and Locke, among others, had then to address the vexing philosophical problem of how our representations - which for them were ideas in our minds - can in some sense correspond to real external entities. They all bestowed the privilege of hitting on external entities to a specific class of representations, namely mathematical representations, further restricted to geometrical representations. The supposed real correlates of mathematical representations, the so-called primary qualities or properties, acquired then a particular aura, at the expenses of the visual, auditory, olfactory, tactile and gustative secondary qualities that were degraded as mere "appearances".

Modern thinkers were well aware that a "representation in my mind" is in itself devoid of truth or falsity. Only claims that an external entity resembles in certain respects my representation of it run the risk of falsity; in compensation they might carry the prize of truth. Despite strong disagreements at the epistemological level, Galileo, Descartes and Locke all embraced the metaphysical thesis that the "real world" is a mechanical, geometrical world of systems, namely a world of entities made of geometrical elements structured by relations of positions and motions. If

Principia 15(3): 461-474 (2011).

Published by NEL — Epistemology and Logic Research Group, Federal University of Santa Catarina (UFSC), Brazil. 
we subscribe to this grand metaphysical vision of the world, the problem of the correspondence between our mathematical representations and structured entities, i.e. systems, in the world is solved. In contemporary language, the correspondence takes the specific form of an isomorphic function (in the case of a one-one correspondence between the elements of my representation and the elements of the represented system) or a homomorphism (when we have a many-one correspondence).

Today, few would still defend the metaphysics of the "mechanistic view of the world", but such a view lingers in some versions of physicalism in which the real world is a huge system, perhaps composed of smaller systems, which is structured by mathematical relations and properties that "cut nature at its joints". These bold ontological pronouncements are unjustified. I also discard the psychological construal of representations as 'ideas in our mind'. But I am happy to grant that, methodologically, an essential part of scientific activity consists in constructing mathematical representations, namely models. Then, the old question presses on: how and what do these representations represent? What - if anything - does correspond to them? According to van Fraassen, we have good reasons to believe that some of our models successfully and correctly represent phenomena, whereas there is no cogent reason to believe that models correspond to real unobservable things. Yet, phenomena are not systems; as a consequence, it makes no sense to speak of a homomorphism between a phenomenon and a model. We are then confronted to what van Fraassen names the "Loss of Reality Objection": how can an abstract mathematical structure represent a concrete real phenomenon and not merely the phenomenon as described by the theory? (van Fraassen 2008, p. 258).

In this paper, I will first briefly present what I take to be the representational démarche of science. I will then stress the fundamental role of judgements in model construction. After this, I will criticize van Fraassen's answer to the "Loss of Reality Objection" and offer an alternative answer. I will conclude with some remarks on scientific realism.

\section{How science proceeds}

Let us start, as seems to be fit, with observable phenomena with which we can be immediately acquainted in sensory perception. And let us follow van Fraassen in adopting a natural and healthy "common sense realism" about observed entities such as desks, gases, mountains, planetary motions and the like (van Fraassen 2010, p. 548). Thus, van Fraassen and myself agree to disagree with the modern thinkers, their distinction between geometrical and secondary qualities and the ontological privilege they conferred to the former.

The scientific démarche begins by seeing the observable phenomenon as a system,

Principia 15(3): 461-474 (2011). 
that is, a set of parts organized or structured by some relations. This I called the 'inaugural' or 'original' abstraction (Ghins 2009). Next, some properties of the parts and specific relations among those properties are selected. Within the mechanistic perspective, only primary - geometrical — qualities and relations were considered to be of interest because they were supposed to be real properties of entities in the world. Nowadays, obviously, many other kinds of properties are selected for constructing scientific models. Of course, in selecting some properties in the mess and thickness of phenomena, we assume that the entities observed do have those properties. In other words, we select properties that we feel entitled to believe that they are possessed by those entities. Take my phenomenal desktop. Is it true that it has sides? Yes. Do these sides have lengths? Yes. Are these sides related by an observable order relation among them? Again, yes. I will call predicative judgements that attribute properties to some real entities "ontic judgements".

On this basis, I can construct what I call a "phenomenal structure". The elements of its domain are perceived properties. These properties are organized - structured - by some perceived relations. In the example of the desk, we have a structure of the perceived sides lengths which stand in some ordering relation. Ontic judgements, if true, guarantee that the phenomenal structures refers to some specific target, namely the desk. Although abstracted from the phenomenon, the phenomenal structure is not abstract but concrete in the sense that it denotes a concrete phenomenal entity. The phenomenal structure is not a scientific model yet. But extracting so to speak the phenomenal structure from the phenomenon is a sine qua non condition of possibility for the construction of a scientific model.

At this point, it is appropriate to mention van Fraassen's novel distinction between phenomena and appearances, which he introduces in Scientific Representation:

Phenomena will be observable entities (objects, events, processes). Thus 'observable phenomenon' is redundant in my usage. Appearances will be the contents of observation or measurement outcomes. (2008, p. 8)

In van Fraassen's terminology what I called a phenomenal structure would be an appearance. It expresses the point of view the scientist chooses to adopt when considering a given phenomenon and engaging in the task of constructing a representation of it. For van Fraassen, what I call the phenomenal structure is already a representation of the phenomenon, from a certain vantage point, and it is the result of - admittedly crude - measurements. In the example of the desktop, the phenomenal structure is the set of the perceived sides lengths which stand in the ordering relation " $x$ is larger than $y$ " where $x$ and $y$ are variables ranging over the perceived lengths.

It is evident that the phenomenal desk can be envisaged from other points of view, albeit always as a system of properties, by a modelling scientist. Therefore, van 
Fraassen rightly insists that there is an inescapable indexical or first-person ingredient in model construction (2008, p. 76). I could be interested in other properties of the desktop, such as its colour and hardness, and construct a phenomenal structure on their basis. The phenomenon is open to a wide, even potentially infinite, array of representations. Unlike the putative mechanistic world, phenomena are not carved in a unique fashion which would entail that only one single kind of representation is susceptible to correctly represent them. There is no single right way to represent a given phenomenon. Representing involves a perspectival take on what I intend to represent.

Thus, according to van Fraassen, I represent the phenomenon as such and such. But since representing always involves a representative function (an isomorphism or homomorphism), I claim that it is not the phenomenon which is represented but only the structure that I have decided to abstract from it. On this I disagree with van Fraassen who maintains that "in a truly robust sense models do represent the observable phenomena" (2010, p. 547). My use of the word "representation" is restrictive and technical; it does not correspond to common usage. Representation, in science as in other fields, always rests on the construction of a homomorphic representative function and thus on some structural similarity (Ghins 2010, p. 526; 2011, p. 211) between the representing artefact and the represented. Then, what is represented is not strictly speaking the target of the representation. What is represented is the perspectival structure that I have decided to abstract from the targeted phenomenon. Therefore, the target or the denotation of a representing artefact is not, strictly speaking, represented by it.

Surely, scientists do not rest satisfied with remaining at the level of phenomenal structures. Typically, they perform measurements with instruments designed to associate numbers to the observed properties, such as the perceived lengths. In the case of the desktop, numbers in a specific unit (centimetres, say) are associated to lengths by means of measuring rods. By this procedure, a data model homomorphic to the phenomenal structure can be constructed. The data model of measurement results is a scientific model. When discrete measurements on continuous quantities are performed, scientists smooth out the results to obtain a continuous curve; this is what van Fraassen calls a "surface model" (2008, p. 167). A surface model also is an appearance.

For van Fraassen, the main purpose of science is to construct theories, that is, classes of models which aim at saving the phenomena, i.e. are empirically adequate (1980, p. 12). To save the phenomena is to show that a theory has at least one model which contains an empirical substructure homomorphic to the data model and, in some cases, which are also homomorphic to a phenomenal structure of interest. ${ }^{1}$ (Notice that an empirical substructure is also theoretical).The phenomenal desktop for example can be embedded in the Euclidean space in the sense that this geometric 
theory contains a substructure which is isomorphic to the data model and to the phenomenal structure extracted from the phenomenon.

Summarizing, we can distinguish five levels in model theoretic construction, namely, real observable phenomena, phenomenal structures, data models (and surface models), empirical substructures and embedding theory.

\section{The role of ontic judgements}

Model construction can convey useful information about phenomena only if it is grounded on true ontic judgements. Thus, modelling my desktop relies on the truth of predicative statements - in which I express my judgements — such as "the desktop is four-sided", "two sides are longer than the other two" and so on. By uttering or forming in petto a predicative statement, I judge that some property belongs to the target of the judgement. I will distinguish between statements and judgements in the following way. Statements are impersonal whereas judgements are first-person actions which possess an illocutionary force. When I claim that the desktop has four sides, I make a judgement. Judgements have assertive illocutionary force, whereas statements do not. ${ }^{2}$

A judgement about a phenomenon is true if there is something that exists that makes it true. This "something" is external to the judgement in the sense that the truth of the judgement is not warranted a priori but crucially depends on the real phenomenal entity. Phenomena impose themselves on us, for good or worse, whether we like it or not. Given the meaning of the words we use in our language, the snow is white and not purple, as a matter of fact. This is plain common sense. If I judge that an object is a round tower, and then, on closer examination, I judge that it is square, only one of those judgements is true, and its truth does not depend on my judging the tower to be thus or so. In this innocuous sense, I adopt a correspondence view - which is distinct from a theory — of truth. There is something "out there" - real phenomenal entities — that are the truth-makers of my judgements.

Such a correspondence view of truth involves no commitment to the existence of properties in the phenomena, or properties instantiated by them, which would make the judgement true. Thus, a correspondence view of truth in this weak sense is to be distinguished from an elaborated correspondence theory of truth which would provide details on how the correspondence obtains if the judgement is true. A paradigmatic example of a (wrong) correspondence theory of truth is to be found in Wittgenstein's Tractatus Logico-Philosophicus. To my knowledge, no satisfactory theory of truth as correspondence has so far been proposed. This situation however cannot count as an objection to the mild correspondence view I advocate. It is somewhat paradoxical that the main argument that we can adduce in favour of

Principia 15(3): 461-474 (2011). 
a correspondence view of truth is our experience of error. At times, we are forced to admit that a judgement we made is false. When this happens, our judgements "clash" with reality, as Popper famously said.

Van Fraassen insists, quite appropriately, that representing involves four necessary ingredients. The first is the user, the first-person representing "I". The second ingredient is the artefact that purports to represent - the 'representor'. Third, there is something that is represented, the represented system. Finally, the user can succesfully represent in some context only when the appropriate conventions and background knowledge are in place. In principle, anything can be used to represent anything if the appropriate conventions are contextually conveyed. van Fraassen gives the example of a piece of white paper which could be used as a (impractical) map of Paris provided a correspondence has been established by some user between the irregularities in the paper and streets, avenues, intersections etc. (2008, p. 233)

Moreover, an artefact is deprived of any "illocutionary force". In other words, an artefact taken in itself doesn't present itself as representing something unless it is appropriated by a user that claims that this artefact represents this or that. If we put a sign or a mark on a piece of paper with the purpose of specifying what the artefact represents, we have constructed in fact another artefact and the problem is only pushed one step back (van Fraassen 2008, p. 31). Here, we can draw a parallelism between statements and artefacts which are impersonal, on the one hand, and judgements and representing items which involve first-person acts, on the other hand. To judge and to represent are both actions performed by someone in the first person: I judge and I represent. Thus, in any representative activity, an noneliminable indexical factor blocks any fantasied access to some elusive "view from nowhere" or a "godlike point of view". On this also, I fully agree with van Fraassen.

In Scientific Representation, van Fraassen follows Goodman who in Languages of Art (1968) likens pictures to statements. A picture depicts a subject as such and such just as a statement attributes a property to some item.

[...] Goodman [...] characterizes even pictures as being like statements, depicting a subject (the referent) as thus or so (as with a predicate). [...] Depiction is [also] predication. Since pictures denote things they are, in that respect, like names; but since they depict those things as thus and so, they are also predicates applied to what they denote." (2008, p.16)

However, as van Fraassen is well aware, the analogy can't be pushed too far. A picture, or a representing artefact in general, lacks a truth value, whereas a statement can be true or false. Representations and statements belong to different categories. For an artefact to do the job of picturing, I have to produce or assume a statement stating that this artefact pictures this target as such and such. Success in representing is achieved only when a target of a representor is identified by its

Principia 15(3): 461-474 (2011). 
user. Success, and therefore identification, is grounded on the truth of some predicative ontic judgements. Success necessitates also that the user be able to identify in the representor some properties that refer to properties which might belong to the target, that is, the properties that are referred to by the terms occurring after the "as" in a judgement of the form " $x$ represents $y$ as $z$ ". If the properties $z$ do belong to the target, then the representation may be qualified as correct in some respects. Consequently, a representation can be successful without being correct in this sense, but its success always relies on the truth of some judgements. Spott's caricature of Bismarck succeeds in representing him as vainglorious, no matter whether he was vainglorious or not (van Fraassen 2008, p. 14-5; Ghins 2011, p. 217-19).

\section{The Loss of Reality Objection}

How is it possible that some of our representations, some of our mathematical models correspond to some external reality? Far from dodging this crucial issue, van Fraassen addresses it frontally.

"The most fundamental question is this:

How can an abstract entity, such as a mathematical structure, represent something that is not abstract, something in nature?" (2008, p. 240)

van Fraassen tackles this question in a twofold way. First, he considers theories about natural entities that are not represented by anybody or that are not accessible to us, such as colonies of bacteria in Antarctica a long time ago. Second, he discusses phenomena that are accessible to us, are the subject of actual measurements and are concretely embedded in some theory, like the time evolution of the deer population in Princeton represented by some graph (2008, p. 254-6).

The first case is more likely to entice us to posit metaphysical baggage and to assert the existence of some independent pre-existing structure in nature that determines the unique adequate representation of it. But, as van Fraassen argues, there is no need to posit such independent structure to make sense of our assertion that a theory is empirically adequate. The theory is adequate if it contains a model an empirical substructure, that is - which is homomorphic to the possible measurements that could have been performed.

In concrete setting - which is the second case - it becomes more difficult to invoke some "metaphysical flora and fauna" (2008, p. 242) in order to make sense of our claims of empirical adequacy. Yet, a metaphysician could object:

Oh, so you say that the only 'matching' is between data models and theoretical models. Hence the theory does not confront the observable phenomena, 
those things, events and processes out there, but only certain representations of them. Empirical adequacy is not adequacy to the phenomena pure and simple, but to the phenomena as described!

An empiricist account of what the sciences are all about must absolutely answer this objection. Let us therefore honour it with a special name: the Loss of Reality Objection (2008, p. 258).

van Fraassen rejects the correspondence view of truth. For him, judgements are our linguistic reactions to the phenomena we are confronted to (2002, p. 134). Surely, our judgements can be true or false and their truth or falsehood doesn't depend only on us. Yet, phenomena are observed by us and for van Fraassen we have no reason to believe in the existence of anything beyond what is observable (by us). Thus, in order to answer the loss of reality objection, it suffices to show that the very formulation of the objection rests on the presupposition of the existence of an "independent reality" which lies besides, beyond or behind the phenomena. For an empiricist, such a presupposition is unjustified and even meaningless. Even worse, such a presupposition gives rise the unnecessary and intractable philosophical problem of the correspondence of our representations with some "external reality". Shouldn't this be enough, it can be added that the presupposition is useless: it doesn't do any philosophical job. In fact, as van Fraassen contends, the loss of reality objection is easily dissolved by showing that if we claim that a theory is adequate to the phenomenon as represented by us and at the same time assert that it is not adequate to the phenomenon, then we are condemned to pragmatic incoherence.

"For us the claims

(A) that the theory is adequate to the phenomenon and the claim

(B) that it is adequate to the phenomenon as represented, i.e. as represented by $u s$,

are indeed the same!"

That (A) and (B) are the same for us is a pragmatic tautology. That it holds depends crucially on who the indexical word "us" functions to denote in an assertion. Appreciating that the equivalence for us is a pragmatic tautology removes the basis for the Loss of Reality objection. (2008, p. 259)

True, we can't claim that a theory is empirically adequate to some phenomena and yet raise doubts about the correctness of an empirical substructure representing a data model or surface model that we have decided to extract from the phenomena.

\section{The objection well lost}

In his offered pragmatic dissolution of the loss of reality objection, van Fraassen considers the relation of a theory to some phenomena. A theory contains empirical 
substructures and these may - or may not - be homomorphic to some data models. At this level, we can meaningfully speak of representation, as we saw above, since the relata belong to the same categories, namely structures. And indeed, it would be inconsistent to maintain that the theory is adequate to the phenomenon as represented by my theory and to deny in the same breath that my theory is not adequate to the phenomenon. Simply because empirical adequacy is just the correct matching of my representing artefact - the empirical substructure — with my data model.

However, the relation of empirical adequacy of a theory to a phenomenon is not the same kind of relation as the relation of a data model or a phenomenal structure, with a phenomenon. It is at this point that the issue of the relation between something concrete - the phenomenon — and an abstracted structure becomes pressing and deserves close examination.

Before we do this, let us underline and discuss an important difference between scientific representations and pictures. Whereas a picture shares some of its visual properties with some visual properties of its target, such resemblance is generally absent in scientific representation. It would be far-fetched to maintain that the results of length measurements resemble the perceived sides of my desk, whereas perceived straight lines in a picture visually resemble the perceived sides of the desk. This is the reason why scientific representation seems to be more vulnerable to the loss of reality objection.

Nevertheless, the loss of reality objection can also be raised with respect to picturing. Any picture neglects and highlights certain traits of the phenomenal target it denotes (but doesn't picture or represent...). Thus, there is always something of the target that is lost. A picture is never complete. When I claim - in common language - that an artefact pictures a desk, such a claim is always elliptic. I mean that the picture denotes a desk to which it resembles in specified respects. The truth of this claim depends on the truth of some other assertions. I take for granted that some conventions are in place that permit to select the relevant respects in the picture and also that the relevant corresponding properties do belong to the picture and its denoted target. In assuming all that, I have tacitly constructed an homomorphism between two structures of properties, one abstracted from the picturing artefact and the other abstracted from the target. Then, we can properly talk of a relation of representation.

To repeat, in order to be able raise the very question of the connection of a representation with reality, we need two structures. As a consequence, the real, concrete, phenomenon seems to have been lost in the process. But if we reason in terms of judgements, the question of the correspondence with reality - and therefore the loss of reality objection - vanishes. Representation, if it is to have some informational content, rests on true judgements. If I claim that "the desk is four-sided" and 
if my judgement is true, then the desk is four-sided. If I deem useful to further construct a representation in some context, fine. But the informational content, and the practical usefulness, of my representing artefact is grounded on some judgements whose truth crucially depends on the existence of some phenomenal entity, and its existence only. There is no need to posit the existence of an "independent reality" hidden behind the phenomenal entity.

How can we then interpret a judgements like this: "this picture represents the desk as yellow"? (Y) The truth of this judgement presupposes the truth of other judgements about the picture, the desk and the properties that are put in correspondence. Given those truths, it is possible to identify what the representing artefact denotes or refers to, namely its target. In order to "represent the desk as yellow" the picture must have some specific property ${ }^{3}$ that is put in correspondence with a purported property of the desk. Again, this is expressed in judgements which capture the usual meaning of sentence $Y$, which can then be said to be reduced to those judgements. $\mathrm{Y}$ is true or false irrespective of the fact that the desk is yellow or not. The question of the actual colour of the desk is left open. But there must be a property of the picture that the speaker associates to a possible property of the desk. Thus, if I assert that a representing artefact represents its target as such and such, I'm not committed to the claim that the target is in fact such and such, but I'm committed to claims about the representor, the representing artefact.

If we realize that successful and correct representations are necessarily buttressed by true judgements, the issue of the contact with reality doesn't arise with respect to representations but with respect to judgements. Certainly, judgements involve an irreducible indexical ingredient just as representations do. Yet, if $I$ judge that my desk is rectangular and that it is brown, these claims are true in virtue of the independent existence of the desk and the loss of reality objection is lost.

\section{Scientific representation}

In general, scientific representations are not pictures. Data models are constructed by means of measurement results which can homomorphically correspond to some properties organized in what I called a phenomenal structure. The problem of realism - or the loss of reality concern - can then be framed thus: is it true that a given phenomenal target possesses this or that quantitatively measured property? For example, is it true that the surface of my desk is equal to $2.11 \mathrm{~m}^{2}$ ?

The theorizing of the target can be pursued several steps further by constructing encompassing theoretical models which contain empirical substructures susceptible to represent surface models or data models. If the empirical substructures match the data models extracted by measurements from phenomena, i.e. if they correctly repre-

Principia 15(3): 461-474 (2011). 
sent them, we are in a position to claim, following van Fraassen, that the phenomena have been embedded in the theory and that the theory is empirically adequate. So far so good. What about realism now? Or, in other words, what are the claims that can be legitimately believed to be true about the phenomenal target?

First, we may question the accuracy of our measuring procedures. But if we have been careful enough and employed reliable instruments, then we have no reason to doubt the truth of judgements about, say, the deer population in Princeton at some specific times. Second, I can question the truth of a law, like for example the form of the curve that is supposed to describe the evolution in time of the deer population in function of several factors. Or, to take another example, I may raise doubts about the truth of the claim that gases behave in accordance to Boyle-Charles-Mariotte law. Irrespective of the answers we give to these questions, the issue of realism hinges on the truth of some judgements, and only derivatively on the success and correctness of some representations.

When van Fraassen offers his pragmatic dissolution of the loss of reality objection, he considers, as we saw above, the adequacy of a theory with phenomena. But to construct an adequate theory, I must construct an appearance, that is, a data model, which is always a perspective taken from my specific vantage point. For this reason, in practice, I must always assert (or deny) both that the theory is empirically adequate to the phenomena and that it is empirically adequate to the phenomena as represented by me. If a accept this, doesn't my disagreement with van Fraassen turn out to be merely verbal?

I don't think so. Recall that I deny that we represent phenomena. If so, what we represent are appearances of the phenomena only. van Fraassen readily grants: "The measurement outcome shows not how the phenomena are but how they look." (2008, p. 290) Even though I concede that a measurement involves some perspective on a given phenomenon, a judgement, if true, says something about what a phenomenal entity is. Thus, even if judgements are irreducibly mine, they can be true of real desks, gases, moving bodies and so forth. Sure, when I say that a gas has some pressure, I leave out its colour or smell, but my claim is true or false according as the gas has or hasn't that particular pressure. And if the pressure of the gas is one atmosphere, this is true not just for me, but for anyone who utters that judgement. Besides, as a matter of fact, the gas has some pressure independently of possible judgements performed by humans.

When I measure that a massive body has velocity $v$ in a particular reference frame, it is true or false that the body has velocity $v$ in this reference frame. This velocity is the same in frames with different origins which are relatively at rest but not in frames in relative motion. For light, the situation is different. Its velocity $c$ is invariant for frames that are in relative constant motion. The point I'm trying to make is this. There is no difference in nature, but only a difference in degree when 
we move away from phenomenal properties to scientific and theoretical properties. In other words, at each level of her or his representational activity, the scientist is only dealing with appearances, in van Fraassen's sense, that is, with what appears relatively to a certain point of view. Despite of this, and this is what a realist like myself wishes to maintain, the observed entities - the phenomena - have or have not certain quantitative properties.

Such a position involves no commitment to some unique butchering of nature at its joints, or even to an unique structure in phenomena. Since there are several ways to abstract properties from phenomena, there are accordingly a plurality of manners of constructing useful and correct representations from them. Any unique metaphysical grand view of the world as being a specific system or structure is unsustainable. But more modest metaphysics is still defensible. It consists in affirming that there are real external entities - phenomenal at least - that have some properties and which crucially determine whether our judgements about them are true or not. Clearly, if I see a red object, the fact that I see it as red depends on some properties of the object, even if it can be argued that my perception doesn't solely depend on those properties.

\section{Scientific realism}

In what precedes, I have mainly addressed the question of the relation of phenomenal structures and data models to phenomena. To conclude, I would like to say a few words on scientific realism. Traditionally, the issue of scientific realism has focussed on the reasons to believe in the existence of some unobservable entities posited by scientific theories and the truth of our judgements about them. Such issue is primarily epistemological. Are we justified in believing that electrons exist and have a mass, a charge and so on? When we deal with phenomena, we can point to an observed "this" or "that" and ask if it has some specific properties: size, colour, hardness etc. But unobservable entities are only knowable by description. If so, it is meaningless to ask if electrons exist without assuming that they might possess some specific properties and that some judgements (typically that their behaviour is described by some laws) about them might be true. Pace Cartwright (1983), entity realism and statement realism sail or sink jointly.

Now, I contend that we have (good) reasons to believe that some observable entities possess a mass and a charge on the basis of some measurement procedures that have proved their reliability. How so? The diverse and independent procedures to measure, say, mass have given concordant quantitative results when applied to a wide variety of phenomenal entities. In the same way as we are entitled to judge that a desk has specific properties by means of various observations performed in

Principia 15(3): 461-474 (2011). 
using several of our senses (seeing, touching etc.), we are in a position to assert that a planet or a rolling ball have some specific mass because we have performed independent measurements the results of which are in agreement. As far as electrons and hypothetical unobservable entities are concerned, the only safe way to ascertain their existence is by implementing measurement processes which have proved their reliability when applied to observable entities. We can also resort to measuring methods that are similar to them or that are grounded on previously established theories. Importantly, these methods must be independent from each other and deliver concordant results (Ghins 2009). Then data models can be constructed and we can check whether a theory contains structures that represent them.

Theoretical representations of unobservable systems achieve contact with reality in the same manner as phenomenal structures and data models do. Just as the informational content of phenomenal structures rests on true judgements, a theoretical structure of unobservable properties hit on something real only provided some assertions about unobservable concrete entities are true. True, when we deal with unobservable entities we are unable to extract properties from them in the way we are in a position to do when we deal with phenomena. Yet, the reasons we can adduce in favour of the existence of unobservable and observable entities are the same. They both invoke the variety and agreement in observations.

Representing and modelling are indispensable and highly important components of scientific activity. Such contention is beyond dispute. But by emphasizing the model-theoretic approach of theories, the advocates of the so-called "semantic" view of theories have downsized the importance of true judgements in scientific practice. Certainly, the syntactic approach heralded by the logical positivists and empiricists proved to be too cramped and called for an healthy reaction. But, as so often happens in history, the tip of the pendulum has swung too far in the opposite direction and the "representational view of theories", as we may call it, has shown its limits. As far as the issue of realism is concerned, focussing on models and representations gives rise to the "Loss of Reality objection". I have argued that to address that objection and to preserve realism, we must highlight the crucial role played by true judgements. If our models are to be successful and informative, some judgements about some entities have to be true, in a correspondence sense. The truth of judgements is the soil on which representational activity rests.

\section{References}

Cartwright, N. 1983. How the Laws of Physics Lie. Oxford: Oxford University Press.

Ghins, M. 2009. Realism. Entry of the online Interdisciplinary Encyclopaedia of Religion and Science. 2009. http://www.inters.org

— 2010. Bas van Fraassen on Scientific Representation. Analysis 70: 524-36.

Principia 15(3): 461-474 (2011). 
. 2011. Models, Truth and Realism: Assessing Bas Fraassen's Views on Scientific Representation. In Science, Truth and Consistency: A Festschrift for Newton da Costa - Proceedings of the CLE/AIPS Event 2009. Ed. by Evandro Agazzi, Itala D'Ottaviano and Daniele Mundici. Manuscrito 34: 207-32. http://www.cle.unicamp.br/manuscrito

Goodman, N. 1968. Languages of Art. An Approach to a Theory of Symbols. Second edition. Indianapolis: Hackett Publishing Company, 1976.

van Fraassen, B. 1980. The Scientific Image. Oxford: Oxford University Press.

- 2002. The Empirical Stance. New Haven: Yale University Press.

- 2008. Scientific representation. Paradoxes of Perspective. Oxford: Oxford Univ. Press.

- 2010. Reply to Contessa, Ghins and Healey. Analysis 70: 547-56.

\section{Acknowledgements}

I wish to thank Catherine Elgin for her useful remarks on some issues addressed in this paper, as well as the organizers of the VII Principia International Symposium on Goodman, especially Alberto Cupani, Cezar Mortari and Luiz Henrique de A. Dutra.

$$
\begin{array}{r}
\text { MiCHEL GHINS } \\
\text { Institut Supérieur de Philosophie } \\
\text { Place du cardinal Mercier 14 } \\
\text { B-1348 Louvain-la-Neuve } \\
\text { BELGiQue } \\
\text { michel.ghins@uclouvain. be }
\end{array}
$$

Resumo. Depois de uma breve apresentação do que considero ser a démarche representacional na ciência, enfatizo o papel fundamental, na construção de modelos, de juízos verdadeiros. O sucesso e a correção de uma representação baseiam-se na verdade de juízos que atribuem propriedades a entidades reais visadas, denominados "juízos ônticos". Apresento então o que van Fraassen chama "a objeção da Perda de Realidade". Depois de criticar sua dissolução dessa objeção, ofereço uma maneira alternativa de responder à objeção da Perda de Realidade mostrando que o contato de nossos modelos com a realidade é fundamentado na verdade de juízos ônticos. Concluo examinando a implicação dessa concepção para a questão do realismo científico.

Palavras-chave: Representação; realismo; van Fraassen; modelo; juízos.

\section{Notes}

${ }^{1}$ In science, a data model is often just produced by measurement procedures and it makes little sense to construct a phenomenal structure.

${ }^{2}$ I also adopt the customary distinction between statements and propositions: a proposition is the semantic content of a statement. Thus, statements in different languages can have the same propositional content.

${ }^{3}$ Notice that the picture doesn't have to contain a yellow area in order to represent the desk as yellow. A pink area might do the trick provided the context conventionally specifies that pink is the code for yellow.

Principia 15(3): 461-474 (2011). 